\title{
Effects of Ostertagia ostertagi and omeprazole treatment on feed intake and gastrin- related responses in the calf
}

\begin{abstract}
Infection with the bovine abomasal nematode, Ostertagia ostertagi, results in a loss of acidsecreting parietal cells and an increase in gastric $\mathrm{pH}$. The effects of an experimental infection with Ostertagia and/or daily treatment with omeprazole (OMP) at $2 \mathrm{mg} \mathrm{kg}-1$ bodyweight for four consecutive days (experiment days 24-27, inclusive) on voluntary feed intake, blood and tissue gastrin concentrations, abomasal G-cell numbers, gastric $\mathrm{pH}$, and blood cholecystokinin (CCK) and pepsinogen concentrations were investigated in the calf. Ostertagia-infected calves demonstrated a significant drop in feed intake between days 24 and 27 post-infection $(38 \%$; $\mathrm{P}<0.001)$ and in $\mathrm{G}$-cell numbers $(42 \% ; \mathrm{P}<0.05)$ and significant increases in abomasal $\mathrm{pH}(\mathrm{P}<0.001)$, fundic mucosal weight $(99 \% ; \mathrm{P}<0.01)$, and blood gastrin $(\mathrm{P}<0.05)$ and pepsinogen $(\mathrm{P}<0.0001)$. OMP treatment of worm-free animals resulted in a significant drop in intake between days 24 and $27(30 \%$; $\mathrm{P}<0.001)$ and in G-cell numbers $(17 \%$; $\mathrm{P}<0.05)$ and significant increases in abomasal $\mathrm{pH}(\mathrm{P}<0.01)$ and blood gastrin $(\mathrm{P}<0.001)$. OMP treatment of Ostertagia-infected animals with an existing hypergastrinaemia had no effect on feed intake, abomasal $\mathrm{pH}$, blood gastrin or pepsinogen or abomasal G-cell numbers. Blood CCK concentrations were also unaffected by either Ostertagia infection or OMP treatment. These data suggest that: (a) the depression in feed intake associated with OMP in worm-free calves was not due to a side effect of drug treatment; (b) inappetance in Ostertagia-infected animals is closely associated with the parasite-induced hypergastrinaemia; and (c) the elevation in abomasal $\mathrm{pH}$ was a major factor responsible for the elevated blood gastrin concentrations seen in parasitised and OMP-treated animals.
\end{abstract}

Keyword: Appetite, Cattle-Nematoda, Gastrin, Omeprazole, Ostertagia 